\title{
ЕВРОПЕЙСКАЯ ЭКОНОМИЧЕСКАЯ КОМИССИЯ ООН В КОНТЕКСТЕ ПОВЕСТКИ ДНЯ В ОБЛАСТИ УСТОЙЧИВОГО РАЗВИТИЯ НА ПЕРИОД ДО 2030 г.
}

Аннотация. В статье анализируется роль Европейской экономической комиссии ООН (ЕЭК ООН) и основные направления её деятельности по реализации Повестки дня ООН в области устойчивого развития на период до 2030 г. Автор обращает внимание на то, что в этом контексте на глобальном и на региональном уровнях она вносит значительный вклад в развитие и гармонизацию международно-правовых норм и стандартов в международной торговле, окружающей среде, статистике, сельском хозяйстве, коммериии, энергетике. Особое внимание уделяется процессам интеграчии по линии ЕС - ЕАЭС. В частности, отмечается последовательная линия Комиссии на включение ЦУР ООН в стратегическую повестку ЕЭК ООН и Евразийского Экономического Союза (ЕАЭС) и повышение координирующей роли ЕЭК ООН в разработке и реализации «Повестки-2030» на пространстве ЕАЭС. Делается вывод, что активное подключение ЕЭК ООН и Евразийского экономического союза к реализации ЦУР через интеграциионные процессы усиливает политическое влияние и конструктивную роль ЕЭК ООН в продвижении интеграционных общеевропейских процессов без разделительных линий.

Ключевые слова: Повестка дня в области устойчивого развития на период до 2030 года, Европейская экономическая комиссия, интеграџионные прочессы, международные $и$ региональные партнеры.

\section{Цели и задачи Европейской экономической комиссии ООН в контексте «Повестки-2030»}

1 января 2016 г. официально вступили в силу 17 целей в области устойчивого развития (ЦУР), изложенные в Повестке дня в области устойчивого развития на период до 2030 г. («Повестка-2030»). Сама Повестка была принята мировыми лидерами в сентябре 2015 г. на саммите $\mathrm{OOH}$.

Важную роль в реализации «Повестки-2030» на европейском континенте призвана сыграть Европейская экономическая комиссия ООН (ЕЭК ООН). ${ }^{1}$ Ключевым положением мандата Комиссии (ЕЭК ООН $)$ - многосторонней международной площадки для

(C Щербак Игорь Николаевич - кандидат исторических наук, ведущий научный сотрудник Отдела европейской безопасности Института Европы РАН; ведущий научный сотрудник ИМИ МГИМО МИД России. Aдрес: 125009, Россия, Москва, ул. Моховая, д. 11, стр. 3. E-mail: inshcherbak@gmail.com.

DOI: http://dx.doi.org/10.15211/vestnikieran420197480

${ }^{1}$ ЕЭК ООН учреждена 28 марта 1947 г. Деятельность Комиссии сосредоточена в рамках восьми подпрограмм транспорт; устойчивая энергетика; торговля; экономическое сотрудничество и интеграция; леса и лесная отрасль; окружающая среда; жилищное хозяйство, землепользование и народонаселение; статистика. В состав Ко-миссии входят 56 государств, включая страны Европы, Северной Америки (США и Канада), бывшего СССР, а также Турция и Израиль. Секретариат Комиссии возглавляет Исполнительный секретарь ЕЭК ООН в ранге заместителя Генерального секретаря ООН (с 1 июня 2017 г. эту должность занимает Ольга Алгаерова Словакия). 
практического взаимодействия по вопросам отраслевого сотрудничества - является содействие устойчивому развитию и экономическому процветанию государств-членов, а также их экономической интеграции и сотрудничеству. В силу междисциплинарного характера своего мандата ЕЭК как международная организация системы ООН идеально приспособлена для результативной работы применительно к Повестки дня в области устойчивого развития на период до 2030 г. В частности, речь идёт о таких целях устойчивого развития (ЦУР) как хорошее здоровье; чистая вода и санитария; недорогостоящая и чистая энергия ; достойная работа ; индустриализация, инновации и инфраструктура ; устойчивые города и населённые пункты ; ответственное потребление и производство; борьба с изменением климата; сохранение экосистемы суши ; партнёрство в интересах развития.

Востребованность ЕЭК ООН в контексте «Повестки-2030» объясняется тем, что она вносит значительный вклад в развитие и гармонизацию международно-правовых норм и стандар-тов как на глобальном, так и на региональном уровнях в таких областях как международная торговля, окружающая среда, статистика, сельское хозяйство, коммерция, энергетика и т.д.

ЕЭК ООН служит эффективной платформой для сотрудничества правительств и других заинтересованных сторон и их участия в разработке норм, стандартов и правовых документов. Возможности Комиссии опираются на сеть из 1 тыс. 800 экспертов, которые сотрудничают в разработке нормативных документов и обобщают передовой опыт. Специализированная техническая помощь странам способствует более эффективному осуществлению положений этих документов и облегчает их понимание.

При этом нормотворчество ЕЭК ООН имеет не только региональное европейское измерение. В ряде случаев правила и нормы, установленные разработанными в ЕЭК конвенциями и соглашениями, охватывают страны других регионов. Здесь можно сослаться на выработанные в рамках Комиссии более чем 30 проектов технической помощи в различных областях экономики, затрагивающих, в том числе, и другие страны и имеющих практически глобальное измерение.

Комиссия является диалоговой и переговорной платформой. В работе её органов принимают участие не только представители государств, но и представители деловых кругов, что позволяет вырабатывать оптимальные рекомендации по ключевым вопросам, относящимся к ее компетенции.

Принятие Повестки дня в области устойчивого развития до 2030 г., которая заменила реализуемые с 2000 г. Цели развития тысячелетия, потребовало серьёзного и качественного изменения в работе ЕЭК ООН. Если Цели развития тысячелетия в основном были сфокусированы на сокращении бедности в развивающихся странах, то ЦУР направлены на достижение устойчивого развития во всех странах, в том числе, включая европейские страны с высоким и средним уровнем дохода. Отличительной особенностью Повестки является также более значительный тематический и отраслевой охват (решение экологических проблем, вопросов управления и миротворчества, сбор данных и предоставление статистической информации в отношении реализации ЦУР).

Оптимальным инструментом для координации деятельности государств-членов и ООН становятся региональные платформы для планирования работы по реализации ЦУР. Важная роль в этом плане принадлежит региональной системе $\mathrm{OOH}$, составной частью которой является ЕЭК ООН. В настоящее время ЕЭК стремится к более тесной увязке своей деятельности с глобальными усилиями по достижению Целей устойчивого развития.

С учётом того, что текущая деятельность ЕЭК сосредоточена в восьми подпрограммах

Научно-аналитический вестник ИЕ РАН, 2019, №4 
(транспорт, устойчивая энергетика, торговля, экономическое сотрудничество и интеграция, леса и лесная отрасль, окружающая среда, жилищное хозяйство, землепользование и народонаселение, статистика), секретариат ЕЭК сделал упор на участии в реализации четырёх «сме-жных» с ЦУР приоритетных направлений - устойчивое использование природных ресурсов, устойчивая мобильность и «умная взаимосвязь», устойчивые и «умные» города, обзор и мониторинг ЦУР. Такой подход позволит разработать комплексные модели для «цепочек» ЦУР и углубить партнёрские отношения со всеми участниками, включая государственно-частное партнёрство (ГЧП).

ЕЭК подключена практически ко всем координационным механизмам системы ООН, призванным согласовать действия системы ООН по реализации ЦУР на региональном уровне. В частности, Комиссия входит в состав Региональной группы ООН по вопросам развития в странах Европы и Центральной Азии (Р-ГРООН) и Регионального координационного механизма ООН для стран Европы и Центральной Азии (РКМ). Эти координационные механизмы в свою очередь служат платформами для разработки плана действий региональной системы ООН по поддержке ЦУР и определения приоритетов в их реализации.

\section{Модели сотрудничества ЕЭК ООН с национальными, международными и региональными партнёрами по ЦУР}

ЕЭК ООН придаёт важное значение развитию партнёрства со специализированными организациями и учреждениями системы ООН в интересах эффективного выполнения Повестки -2030.

Интерес в плане новаторских подходов представляет модель взаимодействия ЕЭК с Международным Союзом Электросвязи (МСЭ) в целях содействия в выполнении ЦУР 11 обеспечение устойчивости городов и населенных пунктов. ЕЭК и МСЭ создали в 2016 г. открытую глобальную платформу «Объединение усилий в целях построения "умных" устойчивых городов» с участием еще 14 учреждений системы ООН. МСЭ разработал набор ключевых показателей деятельности (КРІ) для измерения прогресса в использовании ИКТ, а также в сфере социальной интеграции и равного доступа к услугам, уровня качества жизни и экологической устойчивости.

Одним из новых направлений в сотрудничестве ЕЭК ООН с партнёрскими организациями системы ООН в сфере ЦУР стало совместное участие в разработке и осуществлении конкретных проектов для стран региона. В частности, ЕЭК в партнерстве с ФАО подготовили первый обобщенный реестр владельцев лесных хозяйств, охватывающий 20 млн собственников в странах Европы, Северной Америки и Центральной Азии.

ФАО и ЕЭК ООН также опубликовали обзор состояния лесов на Кавказе и в Центральной Азии ${ }^{1}$.

Важным направлением сотрудничества ЕЭК с международными организациями явилась подготовка в рамках Руководящей группы по статистике ЦУР (КЕС) совместно со статистической службой Европейского союза и Организацией экономического развития и сотрудничества (ОЭСР) «дорожной карты»².

«Дорожная карта» призвана выполнять роль ключевого инструмента в мониторинге и

\footnotetext{
${ }^{1}$ UNECE, Annual Report, 2018. P. 8.

2 «Дорожная карта» состоит из шести разделов (создание механизмов национального сотрудничества; оценка готовности стран к расчёту глобальных показателей ЦУР; разработка региональных, национальных и субнациональных показателей; механизм по представлению данных по показателям ЦУР; укрепление потенциала и информационного взаимодействия по статистике ЦУР).
}

Научно-аналитический вестник ИЕ РАН, 2019, №4 
контроле за реализацией государствами Повестки-2030. Она содержит рекомендации для национальных статистических управлений (HCУ) при подготовке данных по глобальным показателям ЦУР в поддержку обзора и отслеживании прогресса в достижении ЦУР. В ней содержаться рекомендации правительствам оказывать поддержку национальным статистическим управлениям в деле мониторинга ЦУР ${ }^{1}$.

В стратегическом плане учреждение Регионального форума по устойчивому развитию для Европейской экономической комиссии (проведение ежегодных сессий намечено на 2020 и 2021 гг.) было призвано обеспечить решение нескольких важных взаимосвязанных задач в контексте ЦУР.

Во-первых, форум дает возможность использовать его в качестве платформы для обмена политическим опытом и передовой практикой в достижении Целей в области устойчивого развития.

Во-вторых, форум служит эффективным инструментом для завершения процесса национальных консультаций с ЕЭК по ЦУР и выработки оптимальных направлений поддержки государств-членов со стороны ЕЭК и системы ООН в целом. При этом своеобразный контроль со стороны ЕЭК за «исполнительской дисциплиной» государствчленов в деле выполнения их добровольных обязательств по ЦУР осуществляется путем публикации секретариатом ежегодных докладов о ходе осуществления повестки по ЦУР до 2030 г.

В-третьих, форум должен в консультациях с государствами-членами обеспечивать соответствие между деятельностью ЕЭК по выполнению ЦУР и программной работой политического форума высокого уровня по устойчивому развитию под эгидой Экономического и Социального Совета ООН, который должен быть созван под эгидой Генеральной Ассамблеи ООН в сентябре 2019 г.

ЕЭК ООН в ходе своей 68-й сессии сумела обеспечить консенсус государств государств-членов и Комиссии по перспективной совместной работе по реализации ЦУР и стратегическому видению регионального сотрудничества в Европе в этом контексте. В частности, была принята политическая декларация о поддержке дальнейшей деятельности ЕЭК на стыке восьми регулярных программ, сочетающихся с ЦУР: устойчивые города, устойчивое использование природных ресурсов, устойчивая мобильность и умная взаимосвязь, измерение и мониторинг прогресса в достижении ЦУР. Все эти темы носят межсекторальный характер, имеют значительный объединительный потенциал. Они также представляют практический интерес для политиков и экспертов с точки зрения реализации ЦУР в силу схожести этих проблем в странах региона.

\section{ЕЭК ООН и проблемы диалога между ЕС и ЕАЭС в свете «Повестки-2030» и интеграционных процессов}

В контексте развития сотрудничества ЕЭК ООН с региональными партнерами в сфере реализации ЦУР особого внимания заслуживает последовательная линия Комиссии на включение ЦУР ООН в стратегическую повестку ЕЭК ООН и Евразийского Экономического Союза (ЕАЭС) и повышение координирующей роли ЕЭК ООН в разработке и реализации Повестки-2030 на пространстве ЕАЭС. Важным шагом в этом направлении стало проведение ЕЭК в рамках регионального форума по устойчивому развитию (Женева, март 2019) специальной сессии «Евразийская экономическая комиссия: взгляд на инклюзивный рост и

\footnotetext{
1 «Дорожная карта» по разработке статистики о достижении целей в области устойчивого развития, Европейская экономическая комиссия OOH, 2017. URL: www.unece.org-ECECESSTAT20172_R.pdf. Научно-аналитический вестник ИЕ РАН, 2019, №4
} 
устойчивое развитие». Сессия была посвящена вкладу государств-членов ЕАЭС через развитие евразийской интеграции в реализацию «Повестки-2030» и формирование общеевропейского экономического пространства. ЕЭК ООН в целом целенаправленно использует интеграционный потенциал ЕАЭС и совпадение целей ЕАЭС с «Повесткой-2030» для активного продвижения ЦУР в евразийском контексте. Этому во многом способствует принятая главами государств-членов ЕАЭС Декларация о дальнейшем развитии интеграционных процессов в рамках ЕАЭС (декабрь 2018).

Беспрецедентным фактом стала подготовка Евразийской экономической комиссией доклада о показателях достижения ЦУР в странах ЕАЭС, в котором анализируется соответствие приоритетов развития и деятельности Союза задачам в области устойчивого развития в рамках ЦУР на основе взаимодействия национальных программ по ЦУР и экономической интеграции в рамках Союза. В нём указывается, что деятельность ЕАЭС по поддержанию экономического роста, энергетической безопасности, внедрению инновационных решений в производстве и потреблении, углублению промышленной кооперации, совершенствованию транспортной инфраструктуры, а также социального и медицинского обеспечения для граждан напрямую коррелируется с международными задачами в области устойчивого развития.

Интеграционный потенциал ЕАЭС в совокупности с реализуемыми национальными проектами по устойчивому развитию объективно способствует достижению государствамичленами целей устойчивого развития. Успешная региональная интеграция на примере ЕАЭС выступает двигателем экономического развития и ускоряет достижение ЦУР. Наличие эффективного регионального координационного механизма содействует развитию сотрудничества между странами региона в решении схожих проблем в области устойчивости.

Приоритетной задачей ЕЭК ООН в сфере «Повестки-2030» является обеспечение благоприятных условий для взаимодействия интеграционных процессов в Европе в контексте реализации ЦУР. Единое экономическое пространство ЕС-ЕАЭС может значительно снизить геополитическую напряженность на европейском континенте и тем самым содействовать реализации ЦУР, поскольку исчезнет конкуренция между ЕС и ЕАЭС за привлечение новых членов, а также политически мотивированная проблема выбора для «новых соискателей»

В фокусе внимания на перспективу должно быть подключение к этому процессу более широкого круга различных интеграционных объединений, в том числе АСЕАН, ЕС и ШОС и китайской инициативы «Один пояс, один путь».

Несмотря на то, что ЕС и ЕАЭС используют правила и стандарты, разработанные ЕЭК $\mathrm{OOH}$, возможности политического диалога и полноценного сотрудничества между ними в ближайшей перспективе в силу известных обстоятельств практически не просматриваются. Вместе с тем, можно использовать платформу ЕЭК ООН с учетом присутствия там ключевых стран Европейского союза для постепенного налаживания сотрудничества между ЕАЭС и ЕС. Можно было бы, в частности, создать в рамках ЕЭК ООН постоянно действующий механизм для обсуждения и выработки рекомендаций по оптимальным направлениям интеграционного процесса. Этот круг вопросов было бы целесообразно рассматривать на регулярной основе в рамках работы органов ЕЭК ООН.

Взаимоприемлемое решение вышеперечисленных проблем и вызовов, связанных с реализацией ЕЭК «Повестки-2030» применительно к интеграционным процессам может быть найдено в рамках обсуждения на платформе Рабочей группы ЕЭК по политике в 
области стандартизации и сотрудничества по вопросам нормативного регулирования, а также Комитета по внутреннему транспорту ЕЭК ООН. На политическом уровне соответствующие решения или рекомендации могут быть приняты по итогам сессий Регионального форума по устойчивому развитию, а также регулярных сессий ЕЭК и Политического форума высокого уровня по устойчивому развитию.

\section{Выводы}

ЕЭК ООН, деятельность которой на современном этапе тесно увязана с глобальными усилиями по достижению ЦУР, играет одну из ведущих ролей в европейском регионе в плане реализации Повестки в области устойчивого развития до 2030 г.

Комиссия проводит масштабную работу по активному подключению ко всем координационным механизмам, призванным обеспечить согласованность действий системы $\mathrm{OOH}$ на региональном уровне. Созданы горизонтальные и вертикальные механизмы сотрудничества в сфере ЦУР с организациями системы ООН и другими влиятельными региональными организациями, а также с национальными правительствами в целях интеграции национальных, региональных и глобальных планов действий по достижению «Повестки-2030». Сформирована инфраструктура для обмена и предоставления информации и показателей о выполнении ЦУР - принята «дорожная карта» для осуществления мониторинга и контроля за реализацией государствами ЦУР.

Дальнейший прогресс в осуществлении ЕЭК ООН своей деятельности в контексте ЦУР во много будет зависеть от стабильности и устойчивости мировой экономики, преодоления различий между странами региона в темпах социально-экономического развития, геополитической обстановки и успешного функционирования национальных экономик в регионе ЕЭК в контексте параметров «Повестки-2030».

Приоритетной политической задачей для Комиссии является формирование интегрированного общеевропейского экономического пространства без разделительных линий и создание условий для полноценного сотрудничества между ЕС и ЕАЭС как необходимого условия гармоничного развития государств-членов ЕЭК, а также своевременного и полного достижения необходимых показателей ЦУР. Для её решения необходимо активизировать предметное обсуждение на Региональном форуме ЕЭК ООН по ЦУР, на сессиях ЕЭК ООН и в профильных комитетах Комиссии и на других площадках проблемы политического диалога между ЕС и ЕАЭС и принятие рекомендаций, направленных на конструктивное сотрудничество между ними.

Параллельно важно продолжать при содействии ЕЭК ООН диалог по техническим аспектам интеграции в европейском регионе в привязке к ЦУР и в первую очередь в плане гар-монизации технических регламентов и преодолении различий в нормативных положениях.

Необходимо обеспечить координацию деятельности ЕЭК ООН с национальными правительствами и оказать адресную поддержку странам-членам в преодолении имеющихся вызовов, включая стабильное финансирование программной деятельности национальных правительств путем мобилизации дополнительных ресурсов по выполнению ЦУР в привязке к конкретным целям устойчивого развития.

Совместно с национальными правительствами необходимо определить приоритеты в программной деятельности и переориентировать контроль с мониторинга на реальное освоение инвестиций в конкретные ЦУР. ЕЭК ООН предстоит в ближайшей перспективе 
завершить процесс консультаций с национальными правительствами по ЦУР по вопросам поддержки правительств в сфере мониторинга и предоставления информации на основе рекомендаций «дорожной карты».

\section{Список литературы}

«Дорожная карта» по разработке статистики о достижении целей в области устойчивого развития, Европейская экономическая комиссия ОOH, 2017, URL: www.unece.orgECECESSTAT20172_R.pdf.

Ежегодный доклад ЕЭК ООН, 2018

Отчёт об устойчивом развитии 2019 г., Трансформация для достижения целей развития, 28 июня 2019 г. URL: www. sdgindex.org.

\section{References}

UNECE, Annual Report, 2018.

Report on sustainable development, Transformation for achieving development goals, June 28 2019. URL: https:/wwwsdgindex.org.

«Road map» on statistics for achieving development goals, UNECE, 2017. URL: www. unece.org-ECECESSTAT20172_R.pdf.

\section{The UN European economic commission in the context of the 2030 agenda for sustainable development goals}

Author. Igor Shcherbak, Candidate of Sciences (History), Leading Research Associate of the Department of European Security, Institute of Europe, Russian Academy of Sciences, Leading Research Associate, IMI MGIMO. Address: 11-3, Mokhovaya str., Moscow, Russia, 125009. Email: inshcherbak@gmail.com.

Abstract. The author studies the role and principal activities of the UNECE in the field of realization of the 2030 agenda for Sustainable Development Goals. Attention is drawn to the fact that the UNECE contributes a lot in the context of the 2030 agenda to development and harmonization of international legal norms and standards both on international and regional levels in the spheres like international trade, environment, statistics, commerce, agriculture, energy. Special attention in this context is devoted to integration processes between the EU and the Eurasian Economic Union. In particular noted the persistent line of the Commission on inclusion Sustainable Development Goals into strategic agenda of the UNECE and the Eurasian Economic Union and on strengthening coordinating role of the UNECE in development and realization of the SDG within the framework of the Eurasian Economic Union. It is underlined that active involvement of the UNECE and the Eurasian Economic Union in realization of the SDG through integration processes increases political influence and constructive role of the UNECE in promotion of the pan European integration processes without dividing lines.

Key words: The 2030 agenda for Sustainable Development Goals, the UN economic Commission, integration processes, international and regional partners.

DOI: http://dx.doi.org/10.15211/vestnikieran420197480 